\title{
Selection of industrial robots using the Polygons area method
}

\author{
Mortaza Honarmande Azimi $^{a^{a}}$, Houshang Taghizadeh ${ }^{\mathrm{b}}$, Nasser Fegh-hi Farahmand ${ }^{\mathrm{b}}$ and Jafar \\ Pourmahmoud $^{\mathrm{c}}$
}

${ }^{a}$ Department of Management, College of Management, Economics \& Accounting, Tabriz Branch, Islamic Azad University, Tabriz, Iran

${ }^{b}$ Associate Professor, Department of Management, College of Management, Economics \& Accounting, Tabriz Branch, Islamic Azad University, Tabriz, Iran

${ }^{c}$ Assistant Professor, Department of Applied Mathematics, Azarbaijan Shahid Madani University, Tabriz, Iran

\section{H R O N I C L E}

Article history:

Received January 222014

Received in Revised Format

June 62014

Accepted June 122014

Available online

June 172014

Keywords:

Robot Selection

Multi-attribute Decision Making

(MADM)

Polygons Area Method (PAM)

$S A W$

TOPSIS

VIKOR

$W P M$

\section{A B S T R A C T}

Selection of robots from the several proposed alternatives is a very important and tedious task. Decision makers are not limited to one method and several methods have been proposed for solving this problem. This study presents Polygons Area Method (PAM) as a multi attribute decision making method for robot selection problem. In this method, the maximum polygons area obtained from the attributes of an alternative robot on the radar chart is introduced as a decisionmaking criterion. The results of this method are compared with other typical multiple attribute decision-making methods (SAW, WPM, TOPSIS, and VIKOR) by giving two examples. To find similarity in ranking given by different methods, Spearman's rank correlation coefficients are obtained for different pairs of MADM methods. It was observed that the introduced method is in good agreement with other well-known MADM methods in the robot selection problem.

\section{Introduction}

During the past few years, there have been tremendous efforts to use robots for different hard circumstances. Shivanand et al. (2006) define robots as "automatically controlled, reprogrammable, multi-purpose manipulators programmable in three or more axes". Indeed, robots are still novel concept in industry as a whole, and so it is not unusual for an industry to be a first-time robot purchaser (Rao, 2013). Robots with various capabilities and specifications are available for a wide range of applications. Hence, selection of the most appropriate robot has long been a difficult decision task. MCDM methods are the most common approach applied for robot selection (Tansel İç et al. 2013). Multiple Criteria Decision Making (MCDM) is associated with making decisions where there are different and usually conflicting criteria. These methods are divided into two general Multiple Objective Decision Making (MODM) and Multiple Attribute Decision Making (MADM) categories. MODM has decision variables in the form of a continuous variable or an integer. MODM can have one or multiple alternatives, which the selected alternative is the one, which fulfills the constraints of the

* Corresponding author. Tel: +989141130511

E-mail: honarmand@iaut.ac.ir (M. Honarmande Azimi)

(C) 2014 Growing Science Ltd. All rights reserved. doi: $10.5267 /$ j.ijiec.2014.6.001 
problem and satisfaction of the decision-maker (Zanakis et al., 1998). Most MODM methods employ mathematical programming under various criteria. These methods are not easily compatible with problems of the manufacturing environment due to their specific mathematical difficulties. Although many applications and programs have been presented for these methods, lack of simplicity of understanding the theories placed behind them made them an unattractive option for users.

MADM methods are widely applied for real-world problems (Rao, 2007, 2013; Fendel \& Spronk, 1983; Hwang \& Yoon, 1981). Methods such as the Technique for Order Preference by Similarity to Ideal Solution (TOPSIS), Simple Additive Weighting (SAW) or weighted sum model (WSM), Weighted Product Method (WPM) or Multiplicative Exponent Weighting (MEW), Analytic Hierarchy Process (AHP), ELimination Et Choix Traduisant la REalité (ELECTRE), Vise Kriterijumska Optimizacija Kompromisno Resenje (VIKOR), and Linear Assignment are widely used methods. However, these methods have their own advantages and disadvantages (Rao, 2007). Their major deficiency of MADM is that in a single problem, various methods present different results for selection or ranking. By comparing the methods, the researchers found that in $40 \%$ of cases, each method presents a result, which is different from the other one (Voogd, 1983). To solve this problem, some methods have been introduced (Wang et al., 2005; Momeni, 2007; Rao, 2013) known as "aggregation methods". In this method, a problem with several MADM methods is ranked, and then, the final selection may be made on the basis of an aggregation of the results of those methods that have better Spearman's rank correlation coefficients (Rao, 2013). Another way of deciding is to choose an alternative suggested by the "majority" of the MADM methods (Rao, 2013). Based on MADM literature, the reason that researchers seek new methods for decision-making is to enhance selection confidence or ranking methods, which perform the selection or ranking of alternatives easily and reliably, in addition to previous methods.

This study presents the polygons area method for the robot selection problem. In this method, the maximum polygons area obtained from the attributes of an alternative robot on the radar chart is introduced as a decision-making criterion (Honarmande Azimi \& Pourmahmoud, 2012). An advantage of the presented method is simplicity of the algorithm and primary calculations required for finding a decision criterion. The required calculations in this method are easily performed by four basic operations. In addition, the decision-making criterion is obtained based on a concrete and extremely precise method with proven experimental and mathematical formulas. Another advantage of this method is the sound agreement of the results from this method with other major MADM methods. The simplicity of learning and training is another advantage of this method. To show the applicability of this method in robot selection, two examples already studied by other researchers with other MADM methods have been proposed. To demonstrate the high correlation of the results from this method with main MADM methods, Spearman's correlation coefficient has been employed (Sheskin, 2004; Yurdakul \& İç, 2009; Rao, 2013). Investigating the proposed examples indicates the high correlation of ranking results from this method with other MADM methods, and this method can be used along with other main MADM methods due to its simplicity and convenience for robot selection.

\section{Literature Review}

Industrial robot usage by manufactures has increased extensively in the past decades. There are over 75 attributes, which can be considered while selecting a robot (Bhangale et al., 2004). These attributes can be either objective or subjective. Objective attributes include cost, velocity, load capacity of the robot, load carrying capacity, repeatability, memory capacity, manipulator reach, and degree of freedom, which can be measured by numerical values. On the other hand, subjective criteria are qualitative in nature (e.g. vendor's service quality and robot's programming flexibility etc.) (Rao, 2007). A decision maker that can use robots is faced with different alternative robots for a given industrial application. Therefore, selection of a robot becomes an important problem, because improper selection of robots may adversely influences on the profitability of the company (Rao, 2013). There are many models for 
robot selection; different MADM methods can be effectively used to solve this problem (Athawale \& Chakraborty, 2011; Tansel İç et al., 2013). Studies which use MADM methods are presented for robot selection in the Literature (Table 1). As seen in Table 1, MADM methods are the most common approach type applied for ranking robots.

Table 1

Robot selection literature

\begin{tabular}{clcl}
\hline N0. & Name of the authors & Year & Method for robot selection \\
\hline 1 & Agrawal et al. & 1991 & Employed the TOPSIS method \\
\hline 2 & Wang et al. & 1991 & Decision support system applies a fuzzy set \\
\hline 3 & Khouja & 1995 & DEA \\
\hline 4 & Goh & 1997 & AHP \\
\hline 5 & Bhangale et al. & 2004 & Using TOPSIS and graphical methods \\
\hline 6 & Rao and Padmanabhan & 2006 & Digraph and matrix method \\
\hline 8 & kahraman et al. & 2007 & Fuzzy TOPSIS \\
\hline 9 & Karsak & 2008 & QFD and fuzzy linear regression \\
\hline 10 & Shatterjee et al & 2010 & VIKOR \& ELECTRE II \\
11 & Rao and Patel & 2011 & Analytical hierarchy graph theory and matrix approach(AHGTAMA) \\
12 & Devi & 2011 & subjective and objective integrated MADM method \\
13 & Athawale \& Chakraborty & 2011 & Fuzzy VIKOR \\
14 & Tao et al. & 2012 & Fuzzy VIKOR \\
15 & Karsak & 2012 & DEA, AHP,TOPSIS,AFS(axiomatic fuzzy set) \\
16 & Vahdani et al. & 2013 & Fuzzy regression-based decision-making approach \\
\hline 17 & Tansel İç et al. & 2013 & Fuzzy AHP,ROBSEL(ROBot SELection) \\
\hline 18 & Mondal \& Chakraborty & 2013 & DEA \\
\hline
\end{tabular}

The idea of using the polygons area on the radar chart or spider chart as a decision-making criterion has been addressed in industry and management literature in recent decades, most of which are in graphical and non-quantitative form. Results obtained from investigations indicate that few similar investigations have been conducted to find the area of polygons on the radar chart as a decision criterion. Using these methods, Bhangale et al. (2004) ranked robots by representing TOPSIS and graphical method. We can mention Waigaonkar et al. (2008) and Rao and Baral (2011) as later works conducted based on of Bhangale's method. The method proposed by Bhangale et al. (2004) was conducted regardless of placement order of the criteria on the chart and this method had insufficient stability. In other words, variations in area value will result in different decision-making criteria from one order to the other. Thus, since the decision criterion is not stable, therefore, the results will not be acceptable in practice.

Honarmande Azimi and Pourmahmoud (2012) proposed an algorithm to form polygons on the radar chart, which on that basis, the maximum area formed on the chart is considered as a decision-making criterion by an alternative.

This study proposes a method for solving the robot selection problem based on the algorithm presented by Honarmande Azimi and Pourmahmoud (2012). In previous MADM methods presented by researchers, a limited number of studies have been conducted in terms of graphical method, and no method has been presented based on the proposed algorithm. Among the many MADM methods available, in our research, we have chosen SAW, WPM, TOPSIS, and VIKOR methods for comparison. The rationale for selection was that most of these methods are among the more popular and widely used methods (Rao, 2007, 2013; Behzadian et al., 2012). SAW and WPM assume additive and multiplicative weighted preferences in an interval scale (Zanakis et al., 1998); and SAW was selected as the basis for which to compare the other methods, because its simplicity makes it often used by practitioners. Even some researchers argue that SAW should be the standard for comparisons (Triantaphyllou \& Mann, 1989). The MADM methods VIKOR and TOPSIS are both based on an aggregating function representing "closeness to the ideal" (Zanakis et al., 1998). The VIKOR method uses linear normalization; the TOPSIS method uses vector normalization. 
The basic principle of the TOPSIS method is that the solution should have the shortest distance from the ideal solution, and the farthest distance from the negative-ideal solution; however, it does not consider the relative importance of these points (Hwang and Yoon, 1981). VIKOR is a helpful tool in a situation where the decision maker is not able, or does not know how to express their preference at the beginning of system design (Opricovic \& Tzeng, 2004).

\section{MADM Methods}

In this paper, we concentrate on single decision maker deterministic MADM methods. Nowadays, SAW, WPM, TOPSIS, VIKOR, and AHP methods are more widely used in practice. These methods are logical decision-making approaches and have a higher potential to solve decision-making problems in manufacturing environments (Rao, 2007).

\subsection{SAW Method}

This is also called Weighted Sum Method (WSM). SAW is the simplest and the most commonly used approach (Triantaphyllo et al., 1998). Each attribute is given a weight, and the sum of all weights must be one. Each alternative is assessed with respect to every criterion. Then, the performance score of the alternative is obtained using Eq. (1).

$$
S_{i}=\sum_{j=1}^{n} w_{j} x_{i j} \quad \text { for } i=1,2, \ldots, m
$$

where $m$ is the number of alternatives, and $n$ is the number of decision criteria, $x_{i j}$ is the actual value of the $\mathrm{i}^{\text {th }}$ alternative in terms of the $\mathrm{j}^{\text {th }}$ criteria, $w_{j}$ is the weight of importance of the $\mathrm{j}^{\text {th }}$ criterion. This method should be used when all the units employ identical units of measure. If the units of the decision matrix are normalized, then this method can be used for any type of attribute. The overall performance score $\left(\mathrm{S}_{\mathrm{i}}\right)$ of the $\mathrm{i}^{\text {th }}$ alternative is calculated as follows,

$$
S_{i}=\sum_{j=1}^{n} w_{j} x_{i j}^{\prime} \quad \text { for } i=1,2, \ldots, m
$$

where $x_{i j}^{\prime}$ is the normalized value of $x_{i j}$. The alternative having the highest $S_{i}$ value is the best choice (Rao, 2007).

\subsection{WPM Method}

This method is similar to the SAW method. The main difference is that instead of addition, there is multiplication in this method. The overall performance score $\left(\mathrm{P}_{\mathrm{i}}\right)$ for the $\mathrm{i}^{\text {th }}$ alternative is computed as (Rao, 2007):

$$
p_{i}=\prod_{j=1}^{n}\left[x_{i j}^{\prime}\right]^{w_{j}} \quad \text { for } i=1,2, \ldots, m
$$

Here, the normalized value of the $i^{\text {th }}$ alternative on the $\mathrm{j}^{\text {th }}$ criterion is raised to the power of the relative weight of the corresponding criterion. The best alternative is the one having the highest Pi value.

\subsection{TOPSIS method}

Hwang and Yoon (1981) developed TOPSIS. This method is widely used because of its simple and programmable nature. The basic concept of this method is that the proper alternative has the shortest 
Euclidean distance from the ideal solution, and the longest Euclidean distance from the negative-ideal solution. TOPSIS ranks the alternatives according to these two distance measures. More information can be found in Yoon and Hwang (1995). The main steps of TOPSIS are as follows (Rao, 2007; Triantaphyllou et al., 1998):

Step 1: Prepare decision matrix $\left(\boldsymbol{D}=\left[x_{i j}\right]_{m \times n}\right)$

Where $m$ is the number of alternatives and $n$ is the number of criteria, $x_{i j}$ is the actual value of the $\mathrm{i}^{\text {th }}$ alternative in terms of the $j^{\text {th }}$ criteria.

Step 2: Convert $\mathbf{D}$ matrix to normalized decision matrix $\left(\mathbf{D}^{\prime}=\left[x_{i j}^{\prime}\right]_{m \times n}\right)$ using the following equation:

$$
x_{i j}^{\prime}=\frac{x_{i j}}{\sqrt{{x_{i 1}{ }^{2}+\ldots+x_{i n}^{2}}^{2}}} \text { for } i=1,2, \ldots, m \quad j=1,2, \ldots, n
$$

Step 3: Obtain the weighted normalized matrix (V).

$V_{i j}=w_{j} \times x_{i j}^{\prime}$

Where $x_{i j}^{\prime}$ is the normalized value of $x_{i j}$ and $w_{j}$ is the weight of importance $\mathrm{j}^{\text {th }}$ criterion.

Step 4: Determine the ideal (best) and the negative-ideal (worst) solutions as follows:

$$
\begin{aligned}
& V^{+}=\left\{\left[\max _{i} V_{i j} \mid j \in j\right],\left[\min _{i} V_{i j} \mid j \in j^{\prime}\right] i=1, \cdots, m\right\}=\left(V_{1}^{+}, \cdots, V_{n}^{+}\right) \\
& V^{-}=\left\{\left[\min _{i} V_{i j} \mid j \in j\right],\left[\max _{i} V_{i j} \mid j \in j^{\prime}\right] i=1, \cdots, m\right\}=\left(V_{1}^{-}, \cdots, V_{n}^{-}\right)
\end{aligned}
$$

where $V_{j}^{+}$indicates the most preferable alternative and $V_{j}^{-}$indicates the least preferable alternative. $J=(j=1,2, \ldots, n) / j$ is associated with beneficial criteria and $J^{\prime}=(j=1,2, \ldots, n) / j^{\prime}$ is associated with nonbeneficial criteria.

Step 5: Calculate the separation measures of each alternative from the ideal and the negative ideal solutions using the following equations:

$$
\begin{aligned}
& S_{i}^{+}=\sqrt{\sum_{j=1}^{n}\left(v_{i j-} v_{j}^{+}\right)^{2}}, i=1, \ldots, m \\
& \left.S_{i}^{-}=\sqrt{\sum_{j=1}^{n}\left(v_{i j}\right.}-v_{j}^{-}\right)^{2}, i=1, \ldots, m
\end{aligned}
$$

where $\mathrm{Si}+$ is the separation of each alternative from the ideal solution and $\mathrm{S}_{\mathrm{i}}{ }^{-}$is the separation of each alternative from the negative-ideal solution.

Step 6: Calculate the relative closeness to ideal Solution.

The relative closeness of an alternative to the ideal solution is defined as below:

$$
C_{i}=\frac{S_{i}^{-}}{\left(S_{i}^{+}+S_{i}^{-}\right)}
$$


where $\mathrm{C}_{\mathrm{i}}$ is the priority criterion; the alternatives are ranked in descending order.

Step 7: Rank the preference order

Based on the relative closeness measures, the alternatives can be ranked in descending order. Therefore, the best alternative is the one that has the shortest distance to the ideal solution and the farthest distance from the negative-ideal solution.

\subsection{VIKOR method}

The VIKOR method was established by Yu (1973) and Zeleny (2002). The Serbian name is 'Vlse Kriterijumska Optimizacija Kompromisno Resenje' which means multiple criteria optimization (MCO) and compromise solution,. Later, this method was introduced as one applicable technique to implement within MADM (Opricovic, 1998). Opricovic and Tzeng $(2004,2005)$ developed the VIKOR method as an MADM method. This method focuses on ranking and selecting from a set of alternatives in the presence of conflicting criteria. The VIKOR method began with the form of $\mathrm{L}_{\mathrm{P}}$ - metric (Opricovic \& Tzeng, 2004):

$$
\begin{gathered}
L_{p, i}=\left\{\sum_{j=1}^{n}\left[w_{j}\left(x_{j}^{*}-x_{i j}\right) /\left(x_{j}^{*}-x_{j}^{-}\right)\right]^{p}\right\}^{\frac{1}{p}} \\
1 \leq p \leq \infty \quad i=1,2, \ldots, m
\end{gathered}
$$

If we assume the $\mathrm{j}^{\text {th }}$ criteria represents as a benefit

$$
x_{j}^{*}=\max _{i} x_{i j} \quad \text { and } \quad x_{j}^{-}=\min _{i} x_{i j}
$$

The alternatives are denoted as $\mathrm{a}_{1}, \mathrm{a}_{2}, \mathrm{a}_{3}, \ldots, \mathrm{a}_{\mathrm{m}}$ and $w_{j}$ is the weight of the $\mathrm{j}^{\text {th }}$ criterion, where $\mathrm{j}=1,2$, $\ldots, \mathrm{n}$ and $\mathrm{x}_{\mathrm{ij}}$ is the performance score of the $\mathrm{j}^{\text {th }}$ criterion for alternative $\mathrm{a}_{\mathrm{i}}$. The procedural steps for the VIKOR method are as follows:

Step 1: Prepare the decision matrix.

\section{Step 2:}

a) Determine the best $x_{j}^{*}$ and the worst $x_{j}^{-}$values of all criterion functions, $j=1,2, \ldots, n$

b) Calculate $S_{i}$ and $R_{i}$ values,

$S_{i}=L_{1, i}=\sum_{j=1}^{n}\left(w_{j}\left[\left(x_{j}^{*}-x_{i j}\right) /\left(x_{j}^{*}-x_{j}^{-}\right)\right]\right) \quad i=1, \ldots, m$

$R_{i}=L_{\infty, i}=\max ^{m}$ of $\left\{w_{j}\left[\left(x_{j}^{*}-x_{i j}\right) /\left(x_{j}^{*}-x_{j}^{-}\right)\right]\right\} \quad j=1, \ldots, n$

For non-beneficial criteria $, x_{j}^{*}, x_{j}^{-}$can be rewritten as:

c) Calculate $\mathrm{Q}_{\mathrm{i}}$ value

$$
x_{j}^{*}=\min _{i} x_{i j} \quad \text { and } \quad x_{j}^{-}=\max _{i} x_{i j}
$$

$$
Q_{i}=v\left[\left(S_{i}-S^{*}\right) /\left(S^{-}-S^{*}\right)\right]+(1-v)\left[\left(R_{i}-R^{*}\right) /\left(R^{-}-R^{*}\right)\right.
$$

where

$$
S^{*}=\min _{i} S_{i} \quad S^{-}=\max _{i} S_{i} \quad R^{*}=\min _{i} R_{i} \quad R^{-}=\max _{i} R_{i}
$$


$v$ is introduced as weight of the strategy of 'the majority of attributes' (or 'the maximum group utility'). The value of $v$ lies in the range of 0 to 1 . Normally, its value is taken as 0.5 . However, any value from 0 to 1 can be taken.

d) Arrange the alternatives in ascending order, according to the values of Qi, Ri, and Si values. The best alternative is the one having the minimum $Q_{i}$ value.

Condition 1: Acceptable advantage:

$Q\left(a^{\prime \prime}\right)-Q\left(a^{\prime}\right) \geq D Q$

where a" is the alternative with second place in the ranking list by Q; $D Q=1 /(m-1) . m$ is the number of alternatives.

Condition 2: Acceptable stability in decision-making: The alternative a' should also be the best ranked by $S$ or/and $R$. If one of the conditions is not satisfied, then a set of compromise solutions is proposed, which consists of:

- Alternatives a' and a" if only the $C_{2}$ is not satisfied,

- Or alternatives $\mathrm{a}^{\prime}, \mathrm{a}^{\prime \prime}, \ldots, \mathrm{a}^{\mathrm{m}}$ if the $C_{l}$ is not satisfied; and $\mathrm{a}^{\mathrm{m}}$ is determined by the below relation for maximum $m$.

$$
Q\left(a^{m}\right)-Q\left(a^{\prime}\right)<D Q
$$

The alternative having the minimum value of $Q$ is the best alternative. The core ranking result is the compromise-ranking list of alternatives and the compromise solution with the "advantage rate" (Opricovic \& Tzeng, 2004).

\subsection{Aggregate method}

Decision makers are not limited to one method of MADM in critical situations, because various possible MADM methods attain different results. In order to overcome this problem, various methods called aggregate methods have been introduced. These methods include Rank Average method, Borda method, and Copeland method (Momeni, 2007).

The Average Method ranks alternatives based on the average of calculated ranks from different MADM methods. Each MADM method ranks all of the alternatives. If there are $m$ alternatives, each alternative receives $(m-1)$ points for the first choice, $(m-2)$ points for the second choice, and so on. The alternative with the most points is declared winner in the Borda method.

The Copeland Method starts at the end of the Borda method. It calculates the number of losses for all alternatives. Subtracting the number of loses from numbers of wins determines the prominence of any alternatives (Wang et al., 2005). By considering ranking strategies (i.e. rank average, Borda and Copeland methods), and through creating one Partially Ordered Set (POSET), it will reach consensus" (Azar \& Radjab zadeh, 2010).

\subsection{Proposed method: Polygons Area Method(PAM)}

One of the widely used charts in management problems and practical situations is the radar (Spider) chart. This chart graphically shows areas of relative strengths and relative weaknesses, as well as depicting general overall performance. Performance of each alternative in MADM problems can be shown on the radar chart as a polygon. In this paper, we calculate the maximum polygons area obtained as a decision criterion on the radar chart. 
The stepwise procedure of the proposed method is given as follows (Honarmande Azimi and Pourmahmoud, 2012):

Step 1: Prepare decision matrix (D).

For an MADM problem when there are ' $m$ ' alternatives and ' $n$ ' attributes, the general form of decision matrix $(\boldsymbol{D})$ is given as follows:

$$
D=\left[\begin{array}{ccccc}
x_{11} & \ldots & x_{1 j} & \ldots & x_{1 n} \\
\ldots & \ldots & \ldots & \ldots & \ldots \\
x_{i 1} & \ldots & x_{i j} & \ldots & x_{i n} \\
\ldots & \ldots & \ldots & \ldots & \ldots \\
x_{m 1} & \ldots & x_{m i} & \ldots & x_{m n}
\end{array}\right]_{m \times n}
$$

The attributes may be objective, subjective or a combination of both.

Step 2: Normalization/Normalized decision matrix (D')

There are many normalization procedures available in decision-making literature. In the proposed method, the linear normalization procedure is adopted (Rao, 2007). Let $\boldsymbol{x}_{i j}^{\prime}$ for attribute $j$ compared with alternative $i$ as follows:

$x_{i j}^{\prime}=\frac{x_{i j}}{\max \left(x_{i j}\right)}, \quad$ if attribute is beneficial

$$
x_{i j}^{\prime}=\frac{\min \left(x_{i j}\right)}{x_{i j}}, \text { if attribute is non-beneficial }
$$

Using linear normalization for this method, the decision matrix will transform into the following (Rao, 2007; Singh \& Rao, 2011).

$$
D^{\prime}=\left[x_{i j}^{\prime}\right]_{m \times n}
$$

Step 3: Relative importance of attributes $\left(\boldsymbol{W}_{j}\right)$

In MADM methods, it is also required to determine the priority weight $\left(\mathrm{w}_{\mathrm{j}}\right)$ of each criterion such that the sum of weights for all criteria equals one. These priority weights can be determined using AHP or entropy methods (Rao, 2007). A pair wise comparison matrix is constructed using a scale of relative importance. Judgments are entered using the fundamental scale of the analytical hierarchy process (Saaty, 1980).

Step 4: Formation of weighted normalized decision matrix (V)

$V_{i j}=w_{j} \times x_{i j}^{\prime}$

where $w_{j}$ is the weight of $\mathrm{j}^{\text {th }}$ criteria.

Step 5: Calculating maximum area of polygon on the radar chart

The attributes have been considered to form the radar (spider) chart. The attributes are plotted on the axes, and each alternative will form a polygon. From a different set of attributes, different polygons can 
be obtained, which seems to be unacceptable in reality. Hence, the polygon with maximum area is considered as a decision criterion. The polygon with maximum area is obtained using the following algorithm if $n \geq 4$ :

a) In weighted decision matrix (V), for alternative $i$, attributes are ranked from the largest to the smallest in order.

b) An attribute with first raking is introduced over the base axis of the chart.

c) Attributes with even rankings, each having $v_{i j}$ in length and $\theta=2 \pi / n$ angle of its previous attribute, are placed clockwise on the chart in a descending order.

d) Attributes with odd rankings are also placed counter clockwise similar to the previous step.

e) Connecting the points obtained from the two previous steps; draw the irregular polygon on the radar chart.

f) Represent the apexes of irregular polygon by beginning from the first ranking and moving counter clockwise by $v_{i j}$.

g) The area of triangle $\left(\mathrm{S}_{\Delta}\right)$ given SAS (Side, Angle, Side) for example $(\mathrm{a}, \theta, \mathrm{b})$ is calculated as follows (Murray, 1968):

$\mathrm{S}_{\Delta}=1 / 2 \mathrm{ab} \sin \theta$

Divide polygon into $\mathrm{n}$ triangle(s) and calculate the area of each one as follows:

$S_{\Delta}=\frac{1}{2} v_{i j}^{\prime} \times v_{i(j+1)}^{\prime} \operatorname{Sin} \frac{2 \pi}{n}$

h) The area of an irregular polygon is obtained from the sum of the areas of these triangles, and is calculated as follows (Murray, 1968):

$S_{p i}=\frac{1}{2} \operatorname{Sin} \frac{2 \pi}{n}\left(V_{i 1}^{\prime} V_{i 2}^{\prime}+V_{i 2}^{\prime} V_{i 3}^{\prime}+\ldots V_{i(n-1)}^{\prime} V_{i n}^{\prime}+V_{i n}^{\prime} \times V_{i 1}^{\prime}\right)$

where $S_{\mathrm{pi}}$ is the area of polygon for the $\mathrm{i}^{\text {th }}$ alternative on the chart.

Step 6: Selecting the best alternative

The purpose of this step is selecting the best alternative, which is performed with the help of calculated areas of the irregular polygon of $S_{p i} S$. In this formula, all $S_{p i} S$ is a common $(1 / 2 \sin 2 \pi / n)$ value, which can be relinquished from all comparisons.

$C_{i}=S_{p i} / \frac{1}{2} \sin \frac{2 \pi}{n}$

Shifting the priority criterion from $S_{p i}$ to $C_{i} s$, in which $C_{i}$ s are calculated as follows:

$C_{i}=\sum_{j=1}^{n}\left(V_{i j}^{\prime} \times V_{i(j+1)}^{\prime}\right)+V_{i n}^{\prime} \times V_{i 1}^{\prime} \quad i=1, \ldots, m$

b) If the number of attributes $\mathrm{N}=3, \mathrm{C}_{\mathrm{i}}$ is calculated from the $\mathrm{V}$ matrix as follows:

$$
C_{i}=v_{i 1} \times v_{i 2}+v_{i 2} \times v_{i 3}+v_{i 3} \times v_{i 1} \quad i=1, \ldots, m
$$


The best alternative is the one having the highest $\mathrm{C}_{\mathrm{i}}$ value.

Fig. 1 shows the framework of decision making in this paper.

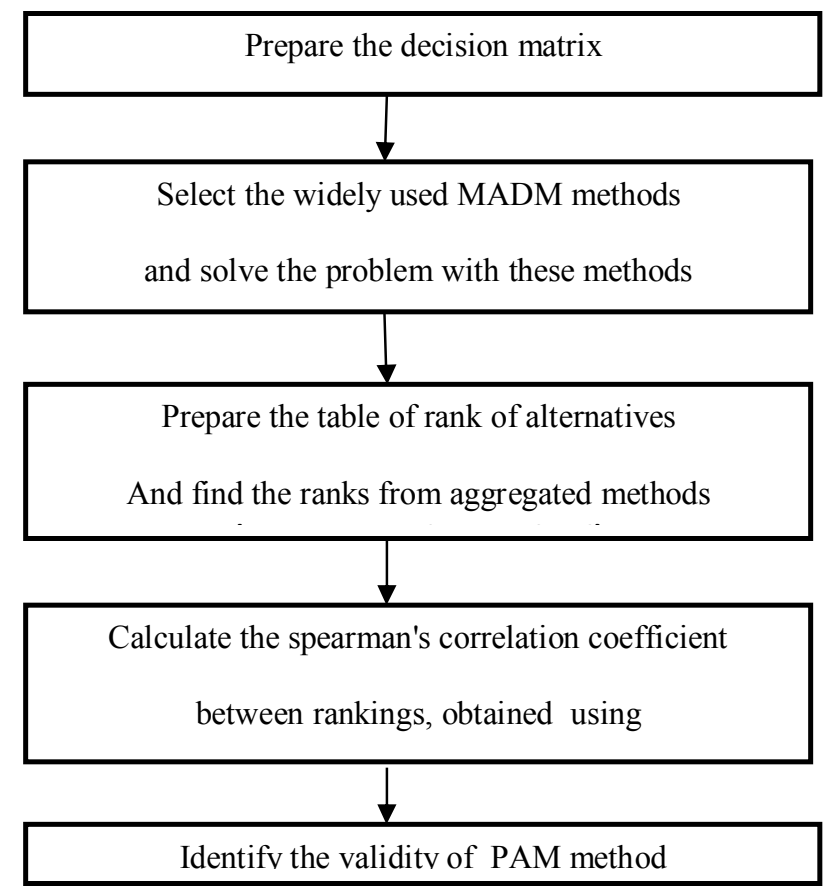

Fig. 1. Framework of decision making

\section{Examples \& Findings}

\subsection{Robot Selection for supporting NC machines}

In this example, a jointed-arm robot is to be selected for supporting Numerical Control (NC) machines. The actual data was provided by the manufactures (Rao, 2007, 2013). Karasak and Ahiska (2005), Rao (2007, 2013), Wang and Chin (2009), Singh and Rao (2011), and Mondala and Chakraborty (2013) solved this example using MCDM methods. The decision matrix with twelve alternative robots and five attributes is given in Table 2. The attributes are Purchasing Cost (PC) in US\$, Handling Coefficient (HC), Load Capacity (HC) in $\mathrm{kg}, 1 /$ REepeatability (RE) in 1/mm, and VElocity (VE) $(\mathrm{m} / \mathrm{s})$, among which HC, LC, RE, and VE are beneficial attributes (where higher values are desirable); whereas, $\mathrm{PC}$ is non-beneficial type (where lower values are preferable).

\section{Table 2}

Decision Matrix (D)

\begin{tabular}{|c|c|c|c|c|c|}
\hline Robots & $P C$ & $H C$ & $L C$ & $R E$ & $V E$ \\
\hline $\mathrm{R} 1$ & 100000 & 0.995 & 85 & 1.7 & 3 \\
\hline R2 & 75000 & 0.933 & 45 & 2.5 & 3.6 \\
\hline R3 & 56250 & 0.875 & 18 & 5 & 2.2 \\
\hline R4 & 28125 & 0.409 & 16 & 1.7 & 1.5 \\
\hline R5 & 46875 & 0.818 & 20 & 5 & 1.1 \\
\hline R6 & 78125 & 0.664 & 60 & 2.5 & 1.35 \\
\hline R7 & 87500 & 0.88 & 90 & 2 & 1.4 \\
\hline R8 & 56250 & 0.633 & 10 & 8 & 2.5 \\
\hline $\mathrm{R} 10$ & 87500 & 0.747 & 100 & 2 & 2.5 \\
\hline $\mathrm{R} 11$ & 68750 & 0.88 & 100 & 4 & 1.5 \\
\hline $\mathrm{R} 12$ & 43750 & 0.633 & 70 & 5 & 3 \\
\hline
\end{tabular}


The normalization of attribute data is carried out using Eq. (18), (19) and the normalized decision matrix (D') is given in Table 3.

Table 3

Normalized Matrix (D')

\begin{tabular}{|c|c|c|c|c|c|}
\hline Robots & $P C$ & $H C$ & $L C$ & $R E$ & $V E$ \\
\hline R1 & 0.281 & 1 & 0.85 & 0.213 & 0.833 \\
\hline $\mathrm{R} 2$ & 0.375 & 0.938 & 0.45 & 0.313 & 1 \\
\hline $\mathrm{R} 3$ & 0.5 & 0.879 & 0.18 & 0.625 & 0.611 \\
\hline $\mathrm{R} 4$ & 1 & 0.411 & 0.16 & 0.213 & 0.417 \\
\hline R5 & 0.6 & 0.822 & 0.2 & 0.625 & 0.306 \\
\hline R6 & 0.36 & 0.667 & 0.6 & 0.313 & 0.375 \\
\hline R7 & 0.321 & 0.884 & 0.9 & 0.25 & 0.389 \\
\hline R8 & 0.5 & 0.636 & 0.1 & 1 & 0.694 \\
\hline $\mathrm{R} 10$ & 0.321 & 0.751 & 1 & 0.25 & 0.694 \\
\hline R11 & 0.409 & 0.884 & 1 & 0.5 & 0.417 \\
\hline $\mathrm{R} 12$ & 0.643 & 0.636 & 0.7 & 0.625 & 0.833 \\
\hline
\end{tabular}

The judgments made by decision makers or relative importance of attributes are given in Table 4 .

The normalized weight of each attribute is obtained from Super Decision software, which are $\mathrm{w}_{\mathrm{PC}}=0.385, \mathrm{w}_{\mathrm{HC}}=0.092, \mathrm{w}_{\mathrm{LC}}=0.042, \mathrm{w}_{\mathrm{RE}}=0.219, \mathrm{w}_{\mathrm{VE}}=0.262$ and consistency ratio $(\mathrm{CR})$ is 0.08 , which is much less than the allowed CR value of 0.1 .

Table 4

The results of judgment

\begin{tabular}{cccccc}
\hline Attributes & PC & HC & LC & RE & VE \\
\hline PC & 1 & 5 & 5 & 3 & $1 / 2$ \\
HC & $1 / 5$ & 1 & 1 & $1 / 6$ & $1 / 3$ \\
LC & $1 / 5$ & $1 / 3$ & 6 & 1 & $1 / 7$ \\
RE & 1 & 2 & 7 & 2 & $1 / 2$ \\
VE & $1 / 3$ & 3 & 7 & 1 \\
\hline
\end{tabular}

Multiplying the (D') by weight matrix, the weighted normalized matrix (V) is given in Table 5.

\section{Table 5}

Weighted Normalized Matrix (V)

\begin{tabular}{ccccc}
\hline Robots & $P C$ & $H C$ & $L C$ & $R E$ \\
R1 & 0.1082 & 0.0920 & 0.0357 & 0.0466 \\
R2 & 0.1444 & 0.0863 & 0.0189 & 0.0685 \\
R3 & 0.1925 & 0.0809 & 0.0076 & 0.1369 \\
R4 & 0.3850 & 0.0378 & 0.0067 & 0.0466 \\
R5 & 0.2310 & 0.0756 & 0.0084 & 0.1369 \\
R6 & 0.1386 & 0.0614 & 0.0252 & 0.0685 \\
R7 & 0.1236 & 0.0813 & 0.0378 & 0.0548 \\
R8 & 0.1925 & 0.0585 & 0.0042 & 0.2190 \\
R9 & 0.1925 & 0.0604 & 0.0105 & 0.1095 \\
R10 & 0.1236 & 0.0691 & 0.0420 & 0.0548 \\
R11 & 0.1575 & 0.0813 & 0.0420 & 0.1093 \\
R12 & 0.2476 & 0.0585 & 0.1818 & 0.1369 \\
& & & 0.1818 & \\
\end{tabular}

Now the proposed PAM method, SAW, WPM, TOPSIS and VIKOR methods are applied to this problem as explained before. Comparison of rankings obtained by these methods is given in Table 7 . The value of $\mathrm{V}_{\mathrm{ij}}^{\prime}$ for PAM is calculated using the introduced algorithm in step 5. For example, the $\mathrm{C}_{1}$ for robot 1 is calculated using Eq. (26) as:

$\mathrm{V}_{11}^{\prime}=0.2182 ; \mathrm{V}_{12}^{\prime}=0.092 ; \mathrm{V}_{13}^{\prime}=0.0357 ; \mathrm{V}_{14}^{\prime}=0.0466 ; \mathrm{V}_{15}^{\prime}=0.1082$

$\mathrm{C}_{1}=\mathrm{V}^{\prime}{ }_{11} \times \mathrm{V}^{\prime}{ }_{12}+\mathrm{V}^{\prime}{ }_{12} \times \mathrm{V}^{\prime}{ }_{13}+\mathrm{V}^{\prime}{ }_{13} \times \mathrm{V}^{\prime}{ }_{14}+\mathrm{V}^{\prime}{ }_{14} \times \mathrm{V}^{\prime}{ }_{15}+\mathrm{V}^{\prime}{ }_{15} \times \mathrm{V}^{\prime}{ }_{11}$

$\mathrm{C}_{1}=0.2182 \times 0.092+0.092 \times 0.03257+0.0357 \times 0.0466+0.0466 \times 0.1082+0.1082 \times 0.2182=0.05368$ 


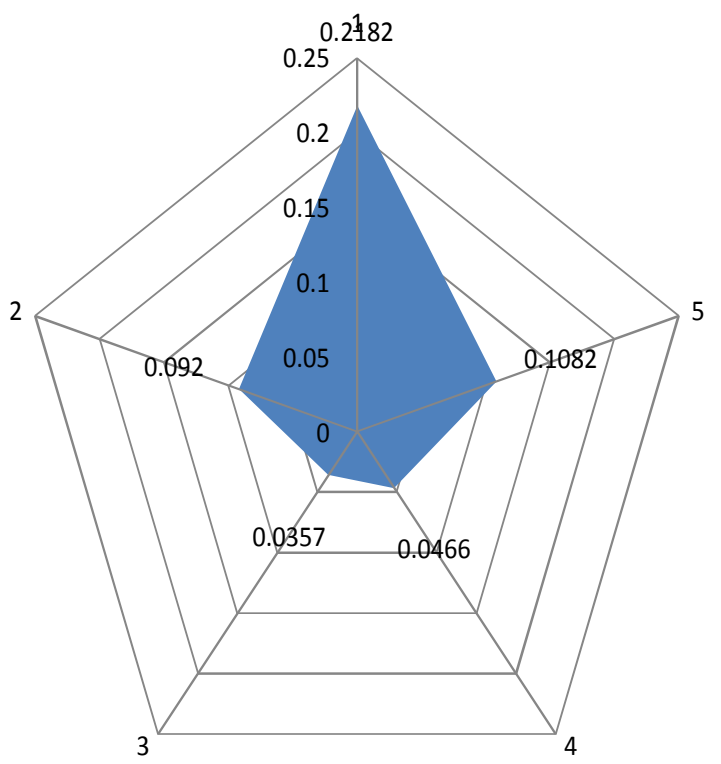

Fig. 2. Polygon area for R1

Table 6

Performance scores using MADM methods

\begin{tabular}{|c|c|c|c|c|c|}
\hline Robots & $S A W\left(S_{i}\right)$ & $W P M\left(P_{i}\right)$ & $\operatorname{TOPSIS}\left(C_{i}\right)$ & $\operatorname{VIKOR}\left(Q_{i}\right)$ & $\operatorname{PAM}\left(C_{i}\right)$ \\
\hline R1 & 0.50077 & 0.41392 & 0.3031 & 0.88431 & 0.05368 \\
\hline $\mathrm{R} 2$ & 0.58012 & 0.51098 & 0.4498 & 0.43169 & 0.07325 \\
\hline R3 & 0.57788 & 0.55836 & 0.5413 & 0.23216 & 0.07175 \\
\hline R4 & 0.58543 & 0.48355 & 0.4892 & 0.47751 & 0.06471 \\
\hline R5 & 0.53207 & 0.49883 & 0.5025 & 0.51023 & 0.06179 \\
\hline R6 & 0.39196 & 0.38159 & 0.2252 & 0.77553 & 0.03242 \\
\hline R7 & 0.39938 & 0.36633 & 0.1736 & 0.88074 & 0.03336 \\
\hline $\mathrm{R} 8$ & 0.65604 & 0.60598 & 0.6769 & 0.12958 & 0.09425 \\
\hline $\mathrm{R} 10$ & 0.47125 & 0.42184 & 0.2811 & 0.77264 & 0.04700 \\
\hline R11 & 0.49954 & 0.47878 & 0.3729 & 0.50426 & 0.05129 \\
\hline $\mathrm{R} 12$ & 0.69058 & 0.68562 & 0.6777 & $-3.7 \mathrm{E}-07$ & 0.10642 \\
\hline
\end{tabular}

Table 7

Robots Rank

\begin{tabular}{|c|c|c|c|c|c|c|c|c|}
\hline Robots & $S A W$ & $W P M$ & TOPSIS & VIKOR & $P A M$ & Average $^{*}$ & Borda $^{* *}$ & Copeland \\
\hline $\mathrm{R} 1$ & 8 & 10 & 9 & 12 & 8 & 10 & 9 & 9 \\
\hline R2 & 4 & 5 & 7 & 5 & 3 & 5 & 5 & 5 \\
\hline R3 & 5 & 3 & 3 & 3 & 4 & 3 & 3 & 3 \\
\hline R4 & 3 & 7 & 6 & 6 & 6 & 6 & 6 & 6 \\
\hline R5 & 7 & 6 & 5 & 8 & 7 & 7 & 6 & 6 \\
\hline R6 & 12 & 11 & 11 & 10 & 12 & 11 & 11 & 11 \\
\hline R7 & 11 & 12 & 12 & 11 & 11 & 12 & 12 & 12 \\
\hline R8 & 2 & 2 & 2 & 2 & 2 & 2 & 2 & 2 \\
\hline R10 & 10 & 9 & 10 & 9 & 10 & 9 & 9 & 9 \\
\hline R11 & 9 & 8 & 8 & 7 & 9 & 8 & 8 & 8 \\
\hline R12 & 1 & 1 & 1 & 1 & 1 & 1 & 1 & 1 \\
\hline
\end{tabular}

*Average of SAW; WPM; TOPSIS and VIKOR methods ranks

**Borda \& Copeland methods for SAW; WPM; TOPSIS and VIKOR methods ranks

Poset: $\mathrm{R} 12>\mathrm{R} 8>\mathrm{R} 3>\mathrm{R} 9>\mathrm{R} 2>(\mathrm{R} 4, \mathrm{R} 5)>\mathrm{R} 11>\mathrm{R} 9>\mathrm{R} 10>\mathrm{R} 6>\mathrm{R} 7$

Karsak and Ahiska (2005) using common weight multi-criteria decision making (MCDM), Wang and Chin (2009) using DEA approach with double frontiers, Singh and Rao (2011) using AHGTMA method, Mondal and Chakraborty (2013) using DEA method identified R12 Robot as the best choice. The best alternative obtained using PAM method is R12, which is the same as the one suggested by previous researchers. This validates the PAM method for decision-making situations of manufacturing environment. 
To find similarity in rankings given by different methods, Spearman's rank correlation coefficients (Sheskin, 2004; Myers \& Well, 2003; Yurdakul \& İç, 2009; Rao, 2013) were obtained for different pairs of the five MADM methods and aggregate methods using SPSS software. Table 8 shows the Spearman's rank correlation coefficients.

Table 8

The results of Spearman's rank correlation coefficients

\begin{tabular}{|c|c|c|c|c|c|}
\hline Method & $S A W$ & $W P M$ & TOPSIS & VIKOR & $P A M$ \\
\hline SAW & 1 & $0.881^{*}$ & $0.881^{*}$ & $0.846^{* *}$ & $0.958^{*}$ \\
\hline WPM & & 1 & $0.972^{*}$ & $0.958^{*}$ & $0.944^{*}$ \\
\hline TOPSIS & & & 1 & $0.909^{*}$ & $0.909^{*}$ \\
\hline VIKOR & & & & 1 & $0.888^{*}$ \\
\hline PAM & & & & & 1 \\
\hline Average & & & & & $.951^{*}$ \\
\hline Borda & & & & & $.958^{*}$ \\
\hline Copeland & & & & & $.958^{*}$ \\
\hline
\end{tabular}

0.000 Correlation is significant at the 0.01 level ( 2 tailed)

**sig. $=0.001$ Correlation is significant at the 0.01 level $(2$ tailed $)$

The values of Spearman's rank correlation coefficients show that there is perfect agreement between the introduced method (PAM) and other typical MADM methods.

\subsection{Robot Selection Example 2}

Mondal and Chakraborty (2013) applied Data Envelopment Analysis (DEA) to solve a robot selection problem in a given industrial scenario while considering seven competitive robot alternatives and five criteria (i.e. repeatability ( $\mathrm{RE}$ in $\mathrm{mm}$ ), load capacity ( $\mathrm{LC}$ in $\mathrm{Kg}$ ), maximum tip speed (MTS in $\mathrm{mm} / \mathrm{sec}$ ), memory capacity (MC in points or steps) and manipulator reach (MR in mm)) as predominant robot selection attributes. Among these, LC, MTS, MC, and MR are beneficial in nature, and RE is the only non-beneficial attribute. Athawale and Chakraborty (2011) estimated criteria weights as $\mathrm{w}_{\mathrm{LC}}=0.1574$, $\mathrm{W}_{\mathrm{RE}}=0.1825, \mathrm{w}_{\mathrm{MTS}}=0.2668 \mathrm{w}_{\mathrm{MC}}=0.2430$, and $\mathrm{w}_{\mathrm{MR}}=0.2043$. The decision matrix with seven robot alternatives and five selection criteria is shown in Table 9.

Table 9

Decision Matrix (D)

\begin{tabular}{|c|c|c|c|c|c|}
\hline Robots & $L C$ & $R E$ & $M T S$ & $M C$ & $M R$ \\
\hline R1 & 60 & 0.4 & 2540 & 500 & 990 \\
\hline $\mathrm{R} 2$ & 6.35 & 0.15 & 1016 & 3000 & 1041 \\
\hline R3 & 6.8 & 0.1 & 1727.2 & 1500 & 1676 \\
\hline R4 & 10 & 0.2 & 1000 & 2000 & 965 \\
\hline R5 & 2.5 & 0.1 & 560 & 500 & 915 \\
\hline R6 & 4.5 & 0.08 & 1016 & 350 & 508 \\
\hline R7 & 3 & 0.1 & 177 & 1000 & 920 \\
\hline
\end{tabular}

Then, the proposed PAM method and SAW, WPM, TOPSIS, and VIKOR methods were applied to this problem as explained before. Comparison of rankings obtained by these methods for this robot selection example is given in Table 11.

Table 10

Performance scores using MADM methods

\begin{tabular}{ccccc}
\hline Robots & $S A W\left(S_{i}\right)$ & $W P M\left(P_{i}\right)$ & TOPSIS $\left(C_{i}\right)$ & PAKOR $\left(Q_{i}\right)$ \\
\hline R1 & 0.58912 & 0.45349 & 0.54464 & 0.5182 \\
R2 & 0.55349 & 0.45695 & 0.50262 & 0.1668 \\
R3 & 0.63891 & 0.53518 & 0.52372 & 0.064012 \\
R4 & 0.45552 & 0.41819 & 0.41568 & 0.0000 \\
R5 & 0.35284 & 0.24333 & 0.32016 & 0.3335 \\
R6 & 0.37695 & 0.26293 & 0.34807 & 0.7909 \\
R7 & 0.35502 & 0.22145 & 0.32295 & 0.8853 \\
\hline
\end{tabular}


Table 11

The results of average of SAW; WPM; TOPSIS and VIKOR methods ranks

\begin{tabular}{|c|c|c|c|c|c|c|c|c|}
\hline Robots & $S A W$ & $W P M$ & TOPSIS & VIKOR & $P A M$ & Average $^{*}$ & Borda & Copeland \\
\hline $\mathrm{R} 1$ & 2 & 3 & 1 & 4 & 2 & 2 & 2 & 2 \\
\hline R2 & 3 & 2 & 3 & 2 & 3 & 3 & 3 & 3 \\
\hline R3 & 1 & 1 & 2 & 1 & 1 & 1 & 1 & 1 \\
\hline R4 & 4 & 4 & 4 & 3 & 4 & 4 & 4 & 4 \\
\hline R5 & 7 & 6 & 7 & 5 & 7 & 7 & 7 & 7 \\
\hline R6 & 5 & 5 & 5 & 6 & 5 & 5 & 5 & 5 \\
\hline R7 & 6 & 7 & 6 & 7 & 6 & 6 & 6 & 6 \\
\hline
\end{tabular}

Bhangale et al. (2004), Rao (2007), Chatterjee et al. (2010), Mondal and Chakraborty (2013) also identified R3 Robot as the best choice. While comparing the obtained rankings with those of the past researchers, excellent consistency is observed. To find similarity in rankings given by different methods, Spearman's rank correlation coefficients were obtained for different pairs of the five MADM methods and aggregate method using SPSS software. Table 12 shows the Spearman's rank correlation coefficients.

Table 12

The results of Spearman's rank correlation coefficients

\begin{tabular}{|c|c|c|c|c|c|}
\hline Method & $S A W$ & $W P M$ & TOPSIS & VIKOR & $P A M$ \\
\hline SAW & 1 & $0.929 * *$ & $0.964 * *$ & $0.786^{*}$ & $1 * *$ \\
\hline Sig. & & 0.03 & 0.00 & .036 & \\
\hline WPM & & 1 & $0.854^{*}$ & $0.922 * *$ & $0.929 * *$ \\
\hline Sig. & & & 0.014 & 0.003 & 0.003 \\
\hline TOPSIS & & & 1 & 0.679 & $0.964 * *$ \\
\hline Sig. & & & & 0.094 & 0.00 \\
\hline VIKOR & & & & 1 & $0.786^{*}$ \\
\hline Sig. & & & & & 0.036 \\
\hline PAM & & & & & 1 \\
\hline \multicolumn{6}{|l|}{ Sig. } \\
\hline Average & & & & & $0.964 * *$ \\
\hline Sig. & & & & & 0.00 \\
\hline Borda & & & & & 1 \\
\hline \multicolumn{6}{|l|}{ Sig. } \\
\hline Copeland & & & & & 1 \\
\hline Sig. & & & & & \\
\hline
\end{tabular}

The values of Spearman's rank correlation coefficients show that there is perfect agreement between the introduced method (PAM) and other typical MADM methods, especially with SAW method.

\section{Conclusion}

Selecting the best robot is an important problem in the industrial environment considering various multiple performance attributes. This paper presents the PAM method using polygons area for solving the robot selection problem. Two numerical robot selection examples were presented to indicate the validity and advantages of the proposed method in comparison with the four well-known MADM methods. Spearman's rank correlation coefficient was obtained for different pairs of MADM methods. Observations showed that the proposed method is in good agreement with the other methods. The two robot selection examples show that the PAM method can derive quite acceptable ranking results to assist decision makers in devising appropriate decisions. This validates the proposed method for decision-making situations of manufacturing environments, and can be extended to other decisionmaking situations. The PAM method can also be used for any type of decision-making problem. PAM is logical and simple to implement when compared to other MADM methods. It is suggested that further researches consider other MADM methods and analyze them comparatively. To rank fuzzy data, fuzzy model of the proposed method can be investigated by researchers in future studies.

\section{Acknowledgement}

The authors would like to thank the anonymous referees for their comments on this paper. 


\section{References}

Agrawal, V. P., Kohli, V., \& Gupta, S. (1991). Computer aided robot selection: the 'multiple attribute decision making approach. The International Journal of Production Research, 29(8), 1629-1644.

Athawale, V. M., \& Chakraborty, S. (2011). A comparative study on the ranking performance of some multi-criteria decision-making methods for industrial robot selection. International journal of industrial engineering computations, 2(4), 831-850.

Azar, A., \& Radjab Zadeh, A. (2010). Application Decision MADM Approach. Danesh Publication, $4^{\text {th }}$ Ed.

Behzadian, M., Khanmohammadi Otaghsara, S., Yazdani, M., \& Ignatius, J. (2012). A state-of the-art survey of TOPSIS applications. Expert Systems with Applications, 39(17), 13051-13069.

Bhangale, P. P., Agrawal, V. P., \& Saha, S. K. (2004). Attribute based specification, comparison and selection of a robot. Mechanism and Machine Theory, 39(12), 1345-1366.

Chatterjee, P., Manikrao Athawale, V., \& Chakraborty, S. (2010). Selection of industrial robots using compromise ranking and outranking methods. Robotics and Computer-Integrated Manufacturing, 26(5), 483-489.

Devi, K. (2011). Extension of VIKOR method in intuitionistic fuzzy environment for robot selection. Expert Systems with Applications, 38(11), 14163-14168.

Fendel, G., \& Spronk, J. (1983). Multiple Criteria Decision Methods and Applications. New York: Spring-Verlag.

Goh, C. H. (1997). Analytic hierarchy process for robot selection. Journal of Manufacturing Systems, $16,381-386$.

Honarmande Azimi, M., \& Pourmahmoud, J. (2012). A new multiple attribute decision making method. The $5^{\text {th }}$ International Conference of Iranian Operations Research Society, Tabriz, Iran, 6567.

Hwang, C. L., \& Yoon, K. (1981). Multiple attributes decision making methods and applications. New York: Springer.

Tansel İç, Y., Yurdakul, M., \& Dengiz, B. (2013). Development of a decision support system for robot selection. Robotics and Computer-Integrated Manufacturing, 29(4), 142-157.

Kahraman, C., Çevik, S., Ates, N. Y., \& Gülbay, M. (2007). Fuzzy multi-criteria evaluation of industrial robotic systems. Computers \& Industrial Engineering,52(4), 414-433.

Karsak, E. E. (2008). 'Robot selection using an integrated approach based on quality function deployment and fuzzy regression'. International Journal of Production Research, 46, 723-738.

Karsak, E.E., \& Ahiska, S.S. (2005). Practical common weight multi-criteria decision-making approach with an improved discriminating power for technology selection. International Journal of Production Research, 43, 1537-1554.

Karsak, E. E., Sener, Z., \& Dursun, M. (2012). Robot selection using a fuzzy regression-based decision-making approach. International Journal of Production Research, 50(23), 6826-6834.

Khouja, M. (1995). The use of data envelopment analysis for technology selection. Computers \& Industrial Engineering, 28(1), 123-132.

Momeni, M. (2007). New topics in operations research. Tehran: University of Tehran publication, $2^{\text {nd }}$ Ed.

Mondal, S. \& Chakraborty, S. (2013).A solution to robot selection problems using data envelopment analysis. International Journal of Industrial Engineering Computations, 4(3), 355-372.

Murray, R. S., \& Liu, J. (1968). Mathematical handbook of formulas and tables. Spiegel-Schaum's outline series.

Myers, J. L., \& Well, A. D. (2003). Research Design and Statistical Analysis, $2^{\text {nd }}$ ed., Lawrence Erlbaum.

Opricovic, S. (1998). Multicriteria Optimization of Civil Engineering Systems. Faculty of Civil Engineering, Belgrade.

Opricovic, S., \& Tzeng, G. H. (2004). Compromise Solution by MCDM Methods: A Comparative Analysis of VIKOR and TOPSIS. European Journal of Operational Research, 156, 445-455. 
Opricovic, S., \& Tzeng, G. H. (2007). Extended VIKOR Method in Comparison with Outranking Methods. European Journal of Operational Research, 178, 514-529.

Rao, P. V., \& Baral, S. S. (2011). Attribute based specification, comparison and selection of feed stock for anaerobic digestion using MADM approach. Journal of Hazardous Materials, 186, 2009-2016.

Rao, R. V., \& Padmanabhan, K. K. (2006). Selection, identification and comparison of industrial robots using digraph and matrix methods. Robotics and Computer-Integrated Manufacturing, 22(4), 373383.

Rao, R.V. (2007). Decision making in the manufacturing environment using graph theory and fuzzy multiple attribute decision making methods. London: Springer-Verlag.

Rao R.V., \& Patel B.K. (2010). Decision making in the manufacturing environment using an improved PROMETHEE method. International Journal of Production Research, 48(16), 4665-4682.

Rao, R. V., Patel, B. K., \& Parnichkun, M. (2011). Industrial robot selection using a novel decision making method considering objective and subjective preferences. Robotics and Autonomous Systems, 59(6), 367-375.

Rao, R.V. (2013). Decision making in the manufacturing environment using graph theory and fuzzy multiple attribute decision making methods, $2^{\text {nd }}$ ed., London: Springer-Verlag.

Saaty, T.L. (1980). The analytic hierarchy process. New York: McGraw-Hill.

Sheskin, D. J. (2004). Handbook of parametric and nonparametric statistical procedures. Chapman and Hall /CRC.

Shivanand, H. K. (2006). Flexible manufacturing system. New Age International.

Singh, D., \& Rao, R. (2011). A hybrid multiple attribute decision making method for solving problems of industrial environment. International Journal of Industrial Engineering Computations, 2(3), 631644.

Tao, L., Chen, Y., Liu, X., \& Wang, X. (2012). An integrated multiple criteria decision making model applying axiomatic fuzzy set theory. Applied Mathematical Modelling, 36(10), 5046-5058.

Triantaphyllou, E., \& Mann, S. H. (1989). An examination of the effectiveness of multi-dimensional decision-making methods: A decision-making paradox. Decision Support Systems, 5, 303-312.

Triantaphyllou, E. (1998). Multi-criteria decision making methods: An operation research approach. Encyclopedia of Electrical and Electronic, 15,175-186.

Vahdani, B., Tavakkoli-Moghaddam, R., Mousavi, S. M., \& Ghodratnama, A. (2013). Soft computing based on new interval-valued fuzzy modified multi-criteria decision-making method. Applied Soft Computing, 13(1), 165-172.

Voogd, H. (1983). Multicriteria Evaluation for Urban and Regional Planning. Pion, London.

Waigaonkar, S., Babu, B. J. C., \& Prabhakaran, R. D. (2008). A new approach for resin selection in rotational molding. Journal of Reinforced Plastics and Composites, 27, 1021-1037.

Wang, M. J. J., Singh, H. P., \& Huang, W. V. (1991). A decision support system for robot selection. Decision Support Systems, 7(3), 273-283.

Wang, Y. M., Yang, J. B., \& Xu, D. L. (2005). A preference aggregation method through the estimation of utility intervals. Computers \& Operations Research,32(8), 2027-2049.

Yoon, K. P., \& Hwang, C. L. (1995). Multiple attribute decision making: an introduction (Vol. 104). Sage Publications.

Yu, P.L. (1973). A class of solutions for group decision problems. Management Science, 19 (8), 936946.

Yurdakul, M., \& Ic, Y. T. (2009). Application of correlation test to criteria selection for multi criteria decision making (MCDM) models. The International Journal of Advanced Manufacturing Technology, 40(3-4), 403-412.

Zanakis, S. H., Solomon, A., Wishart, N., \& Dublish, S. (1998). Multi-attribute decision making: A simulation comparison of select methods. European journal of operational research, 107(3), 507529.

Zeleny, M. (2002). Multiple Criteria Decision Making. New York: McGraw Hill. 